\title{
ANALISIS GCMS TERHADAP SENYAWA FITOKIMIA EKSTRAK METANOL GANODERMA LUCIDUM
}

\author{
Surahmaida $^{* 1}$, Tri Puji Lestari Sudarwati ${ }^{1}$, Junairiah ${ }^{2}$ \\ ${ }^{1}$ DIII Farmasi, Akademi Farmasi Surabaya \\ ${ }^{2}$ Departemen Biologi, Fakultas Sains dan Teknologi, Universitas Airlangga \\ *Email: fahida1619@gmail.com
}

Received 20 October 2018

Accepted 20 December 2018

\begin{abstract}
Abstrak
Penelitian ini bertujuan untuk menganalisis senyawa fitokimia ekstrak metanol Ganoderma lucidum dengan metode GCMS. Tahapan penelitian ini meliputi proses ekstraksi serbuk halus $G$. lucidum menggunakan pelarut metanol dengan metode maserasi selama 3x3 hari dan ekstrak metanol G. lucidum yang didapatkan dianalisis dengan alat GCMS. Senyawa fitokimia yang teridentifikasi oleh GCMS antara lain thiophene, 2-hexyl-; 3-((3Acetoxythyl)-6-acetoxymethyl-2,4-dimethyl)phenyl)-2-methyl-(E)-2-propenyl acetate; 2,7-Diphenylindole; dan 5-(2-Bromophenyl)-7-chloro-2,3-dihydro-1H-1,4-benzodiazepin2-one. Dapat disimpulkan bahwa senyawa fitokimia pada ekstrak metanol G. lucidum memiliki efek farmakologis bagi kesehatan manusia dan aktivitas biologis lainnya.
\end{abstract}

Katakunci: Ganoderma lucidum, senyawa fitokimia, GCMS

\begin{abstract}
This study aims to analyze the phytochemical compounds of methanol extract of Ganoderma lucidum using the GCMS method. The stages of this study include extraction of fine powder G. lucidum using methanol solvent by maceration method for 3x3 days and methanol extract of $G$. lucidum obtained were analyzed by GCMS. Phytochemical compounds identified by GCMS is thiophene, 2-hexyl-; 3 - ((3-Acetoxythyl) -6acetoxymethyl-2,4-dimethyl) phenyl) -2-methyl- (E) -2-propenyl acetate; 2,7Diphenylindole; and 5- (2-Bromophenyl) -7-chloro-2,3-dihydro-1H-1,4-benzodiazepine-2one. It can be concluded that phytochemical compounds in methanol extract of G. lucidum have pharmacological effects on human health and other biological activities.
\end{abstract}

Keywords: Ganoderma lucidum, phytochemical compounds, GCMS

\section{Pendahuluan}

Umumnya masyarakat mengenal jamur Ganoderma lucidum dengan sebutan jamur Lingzhi. Jamur G. lucidum ini masuk ke dalam famili Ganodermataceae dan kelas Basidiomycetes. Jamur saprofit ini tumbuh/menempel di pohon-pohon yang mati atau pohon yang membusuk, seperti di pohon oak, maple, elm, willow dan magnolia (Orole, 2016).

G. lucidum digunakan sebagai jamur obat untuk mengobati berbagai macam penyakit sejak ribuan tahun yang lalu seperti kanker, tumor, hipertensi, infeksi mikroba, peradangan, dan lain sebagainya. Banyak penelitian yang telah dilakukan dan dikembangkan untuk penemuan obat baru dan menguji efek farmakologis dari jamur Ganoderma lucidum bagi kesehatan manusia (Patterson, 2016).

Hal ini disebabkan karena G. lucidum banyak mengandung senyawa fitokimia seperti triterpenoid, polisakarida, asam ganoderik dan senyawa penting lainnya yang dapat digunakan sebagai antimikroba, antioksidan, antivirus, 
antikanker, antitumor dan lain sebagainya (Kamra and Bhatt, 2012).

Fitokimia merupakan senyawa bioaktif kimia yang diproduksi alami oleh tumbuhan melalui metabolisme primer atau metabolisme sekunder. Umumnya fitokimia memiliki fungsi biologis penting diantaranya mempertahankan serangan dari predator seperti serangga, jamur dan gangguan pesaingnya, pelindung dari polusi, stress dan kekeringan. Selain itu, fitokimia bermanfaat dalam kesehatan manusia atau melawan berbagai macam penyakit (Mathai, 2000; Hasler and Blumberg, 1999; Gibson et al, 1998).

Penelitian tentang analisis ekstrak Ganoderma lucidum dengan GCMS telah dilakukan. Hasil penelitian yang dilakukan oleh Kannan et al. (2016), menunjukkan bahwa ekstrak etanol G. lucidum mengandung 20 senyawa fitokimia. Ekstrak etil asetat $G$. lucidum mengandung 13 senyawa fitokimia dan ekstrak nheksana G. lucidum mengandung 18 senyawa fitokimia (Orole, 2016). Kesemua senyawa fitokimia tersebut memiliki efek farmakologis dan aktivitas biologis yang penting.

Berdasarkan latar belakang tersebut, maka peneliti ingin mengidentifikasi kandungan senyawa fitokimia yang terdapat ekstrak metanol Ganoderma lucidum dengan GCMS. Diharapkan dari penelitian ini, potensi senyawa fitokimia yang teridentifikasi bisa digunakan sebagai bahan obat baru untuk kesehatan manusia atau sebagai bahan lainnya yang dapat diaplikasikan di bidang ilmu lainnya.

\section{Metode Penelitian}

Alat dan Bahan

Alat yang digunakan dalam penelitian ini adalah GCMS, neraca analitik, corong, erlenmeyer, toples, pipet ukur, dan gelas ukur.

Bahan yang digunakan adalah jamur Ganoderma lucidum (lingzhi) yang diperoleh dari daerah Bantul Yogyakarta, pelarut metanol, kertas saring dan aluminium foil.
Prosedur Penelitian

Pembuatan Ekstrak Ganoderma lucidum (Harborne, 1998)

Jamur Ganoderma lucidum diperoleh dari daerah Bantul, Yogyakarta. Sampel Ganoderma lucidum dipotong kecil-kecil lalu dihaluskan hingga menjadi serbuk halus. 30 gram serbuk halus G. lucidum diekstrak dengan metode maserasi menggunakan $300 \mathrm{ml}$ pelarut metanol. Proses maserasi dilakukan selama 3 hari sambil sesekali diaduk. Setelah 3 hari, dilakukan penyaringan dengan menggunakan kertas Whatman no. 1 . Dimaserasi lagi dengan menggunakan jumlah pelarut dan lama perendaman yang sama. Dilakukan sebanyak 3 kali ulangan.

Analisis GCMS (Kannan et al, 2016)

Ekstrak metanol G. lucidum kemudian dianalisis menggunakan GCMS Agilent 6980N Network GC System dengan detektor Agilent 5973 inert MSD (70eV direct inlet). Larutan sampel ekstrak metanol G. lucidum sebanyak $2 \mu 1$ diinjeksikan ke GCMS yang memiliki kolom kapiler J\&W Scientific, HP-5MS dengan panjang $30 \mathrm{~mm}$, diameter $0,25 \mathrm{~mm}$ dan ketebalan $0,25 \mu \mathrm{m}$. Gas pembawa helium pada laju alir $1 \mathrm{ml} / \mathrm{menit}$ (konstan) dengan rasio split 1:10. Temperatur oven terprogram yaitu $50{ }^{0} \mathrm{C}$ dan disimpan isothermal selama 5 menit, laju peningkatan menjadi $10{ }^{0} \mathrm{C} /$ menit dan suhu ditingkatkan hingga $280{ }^{\circ} \mathrm{C}$ selama 15 menit. suhu port injector adalah $290{ }^{\circ} \mathrm{C}$ dan antarmuka spektrometer massa yaitu $230{ }^{0} \mathrm{C}$.

Identifikasi senyawa fitokimia menggunakan database Willey versi 7.0 dengan membandingkan antara pola spektrum massa dan pola fragmentasi senyawa referensi yang tersimpan dalam perpustakaan Willey.

\section{Hasil dan Pembahasan}

Gas Chromatography Mass Spectrophotometry (GCMS) merupakan salah satu alat kimia yang banyak digunakan dalam analisis senyawa dalam 
tanaman obat seperti minyak esensial, asam lemak, hidrokarbon, lipid dan lainlain. Metode ini sederhana, sensitif dan efektif dalam memisahkan komponen suatu campuran (Marston, 2007; Chaman and Verma, 2006; De-Fatima et al, 2006; Kaushik et al, 2002). Selain itu, GCMS merupakan alat untuk identifikasi senyawa-senyawa bioaktif yang dapat diandalkan (Johnson et al, 2011).
Pada Tabel 1 dapat dilihat senyawasenyawa fitokimia yang telah teridentifikasi pada ekstrak metanol Ganoderma lucidum oleh GCMS antara lain thiophene, 2-hexyl-; 3-((3Acetoxythyl)-6-acetoxymethyl-2,4dimethyl)phenyl)-2-methyl-(E)-2propenyl acetate; 2,7-Diphenylindole; dan 5-(2-Bromophenyl)-7-chloro-2,3-dihydro1H-1,4-benzodiazepin-2-one.

Tabel 1. Hasil analisis senyawa fitokimia ekstrak metanol G. lucidum dengan GCMS

\begin{tabular}{|c|c|c|l|}
\hline Peak & RT & \% Total & \multicolumn{1}{|c|}{ Nama senyawa } \\
\hline 1 & 21.75 & $5.440 \%$ & Thiophene, 2-hexyl \\
\hline 2 & 29.324 & $29.690 \%$ & $\begin{array}{l}\text { 3-((3-Acetoxythyl)-6-acetoxymethyl-2,4- } \\
\text { dimethyl)phenyl)-2-methyl-(E)-2-propenyl }\end{array}$ \\
\hline 3 & 39.687 & $39.687 \%$ & 2,7-Diphenylindole \\
\hline 4 & 25.183 & $25.183 \%$ & $\begin{array}{l}\text { 5-(2-Bromophenyl)-7-chloro-2,3-dihydro-1H-1,4- } \\
\text { benzodiazepin-2-one }\end{array}$ \\
\hline
\end{tabular}

Dari hasil kromatogram (Gambar 1), terdapat satu senyawa yang komposisinya lebih besar (ditunjukkan dengan \% total yang paling besar, 39,687\%) yaitu senyawa 2,7-Diphenylindole.

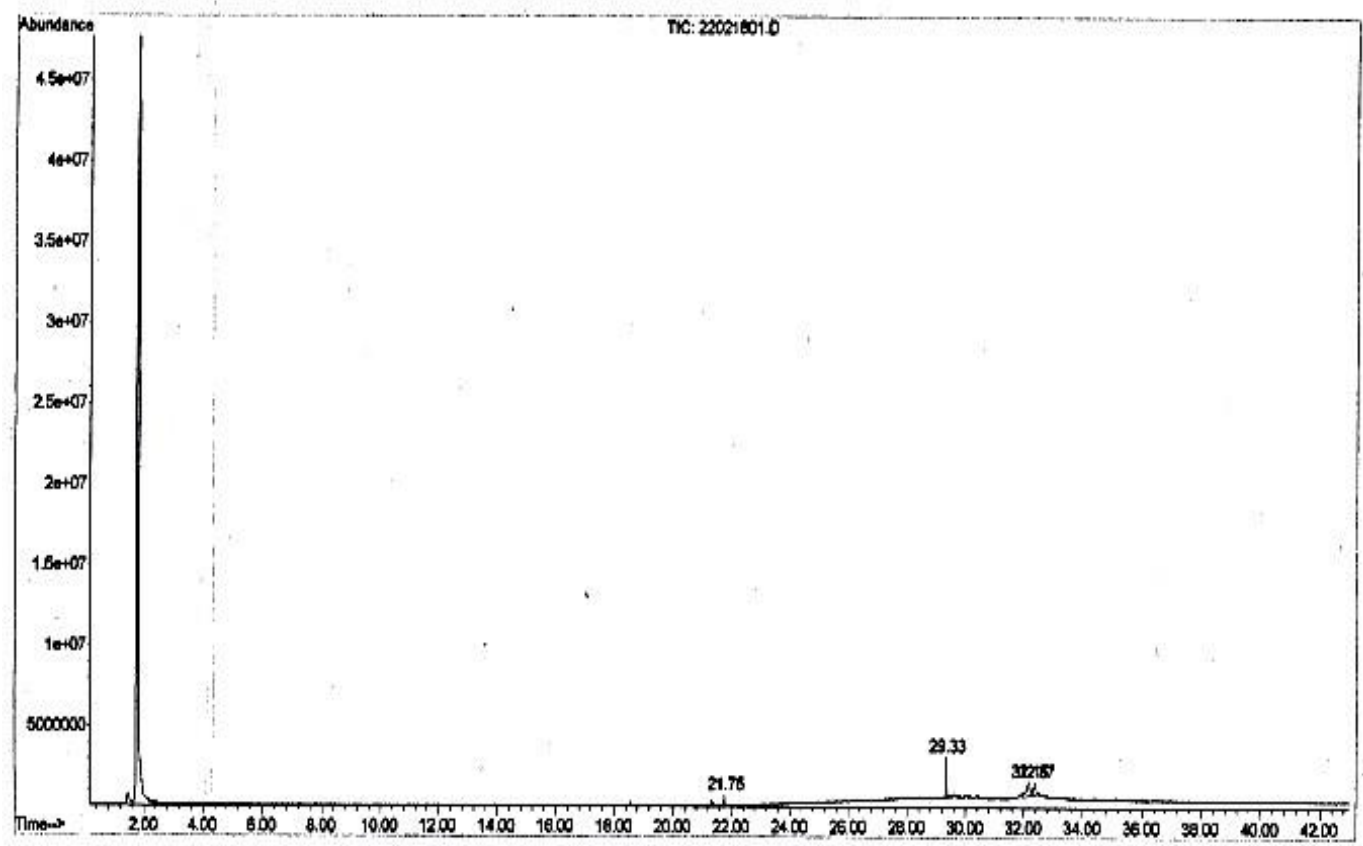

Gambar 1. Kromatogram GCMS ekstrak metanol Ganoderma lucidum

2,7-Diphenylindole termasuk senyawa heterosiklik yang mengandung cincin indol. Senyawa ini terdapat dalam jumlah yang besar (39,687\% pada Tabel 1).

Struktur kimia dari senyawa 2,7- 
Diphenylindole adalah $\mathrm{C}_{20} \mathrm{H}_{15}$ dengan struktur kimia sebagai berikut:

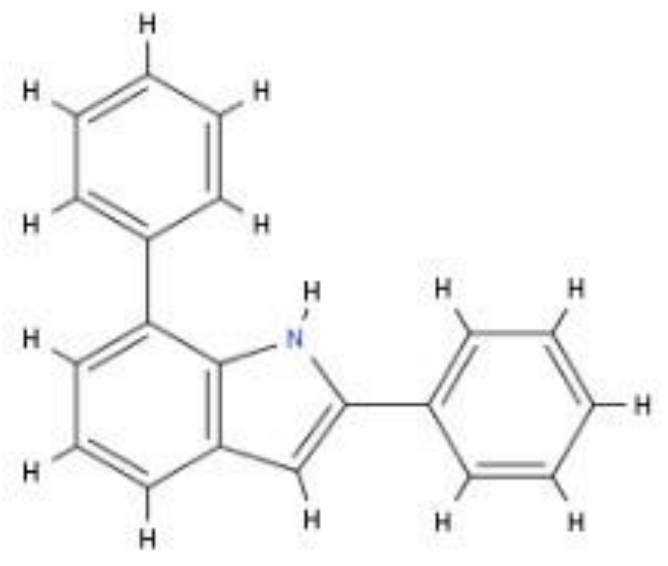

Gambar 1. Struktur 2,7-Diphenylindole (www.chemspider.com)

Senyawa alam yang memiliki cincin indol digolongkan ke dalam golongan senyawa alkaloid. Indol merupakan senyawa heterosiklik aromatik dengan struktur bisiklik. Komponen ini sebagai prekursor dalam bidang farmasi, yaitu obat-obatan (Kumar and Singh, 2013).

Indol alkaloid tersebut memiliki efek farmakologi seperti analgesik, anti alergi, antikonvulsan, antijamur, antihistamin, anti-inflamasi, antikanker, antihipertensi, kardiovaskular, antioksidan (Raju et al, (2015) serta sebagai antibakteri (Gram positif dan Gram negatif) (Cinchana et al, 2011). Contoh dari indol alkaloid adalah tryptophan, sedangkan serotonin dan melatonin adalah molekul-molekul indol yang aktif biologis (Kumar and Singh, 2013).

Senyawa thiophene, 2-hexyl- dan turunannya merupakan senyawa golongan heterosiklik (Mishra and Sharma, 2015).
Senyawa kimia tersebut memiliki efek farmakologis yang menjanjikan (Chaudhary et al, 2012) seperti antikanker (Brown, 1984), antitumor (El-Gaby et al, 1999), antivirus (Roth dan Cheng, 1982), anti-inflamasi dan analgesik (Petrie et al, 1985), serta antimikroba (Nasr dan Gineinah, 2002). Senyawa turunan dari thiophene antara lain thienopyridines (Campos et al, 1999), thienopyrimidines (Abdel-Fattah, 2006) serta thienopyrroles (Sommen et al, 2003; Shimkin et al, 2007) dan kesemua senyawa tersebut telah disintesis/dibuat untuk perkembangan farmakologis baru.

Menurut Illing (2017), senyawa organik heterosiklik yang memiliki cincin piridine digolongkan ke dalam senyawa alkaloid. Struktur 2-hexylthiophene adalah sebagai berikut:

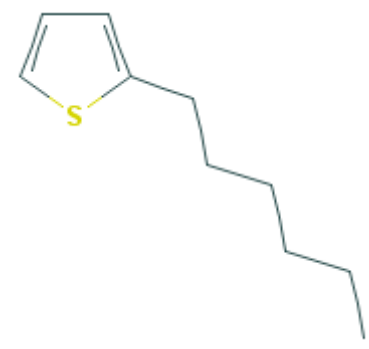

Gambar 2. Struktur kimia 2-hexylthiophene (www.pubchem.ncbi.nlm.nih.gov/compound/2-Hexylthiophene) 
Selain itu, thiophene dan turunannya juga dapat digunakan dalam agrokimia (Ansary, 2001), zat penyedap makanan (www.pubchem.ncbi.nlm.nih.gov/compou nd/2-Hexylthiophene), pengobatan antihipertensi (Mongevega et al, 1980), diabetes melitus (Abdelhamid, 2009) dan antialergi (Burnett et al, 1994).

Senyawa fitokimia yang mengandung 2-Bromophenyl merupakan salah satu contoh dari turunan asam salisilat (Thompson et al, 2012). Asam salisilat merupakan golongan senyawa fenolik (Randjelovic, 2015). Asam salisilat dan turunannya ini bermanfaat bagi kesejahteraan manusia, karena dapat digunakan sebagai anti-inflamasi, antitrombotik, anti malaria, antijamur, herbisida (membasmi tumbuhan pengganggu/gulma) serta merangsang kekebalan tanaman terhadap penyakit (Thompson et al, 2012). Adapun struktur 2-Bromophenyl dapat dilihat pada Gambar 3 berikut:

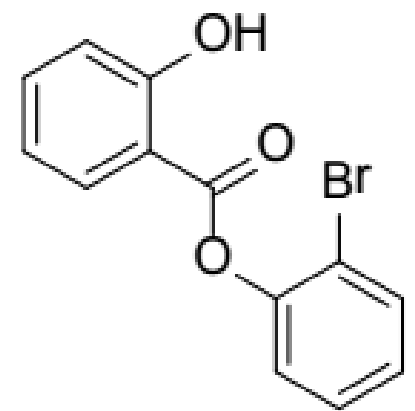

Gambar 3. Struktur 2-Bromophenyl (Thompson et al, 2012)

1,4 benzodiazepine-2-one adalah turunan dari benzodiazepin. Benzodiazepin adalah senyawa kimia yang memiliki cincin heterosiklik, yang merupakan gabungan dari cincin benzen dan diazepin Pada manusia, benzodiazepin bekerja pada sistem saraf pusat, tepatnya pada reseptor gamma-aminobutyric acid-A (GABA-A) di otak dan digunakan oleh saraf untuk berkomunikasi satu sama lain. Aktivitas biologis penting lainnya yaitu senyawa ini banyak digunakan sebagai bahan obat untuk antivirus, AIDS, pengobatan kanker, herbisida serta obatobatan aktif lainnya (Khan et al, 2015; Soria et al, 2006). Hal ini didukung oleh Pi et al (2008), yang menyatakan bahwa 1,4 benzodiazepine-2-one juga digunakan sebagai sedasi (obat penenang), merelaksasikan otot, antikejang ( $\mathrm{Pi}$ et al, 2008). Menurut Umirna (2016), senyawa organik yang memiliki cincin benzen, maka senyawa tersebut dimasukkan ke dalam golongan senyawa fenolik (polifenol). Senyawa-senyawa fenolik (polifenol) diantaranya fenol sederhana, kumarin, asam fenolat, tannin dan flavonoid.

Senyawa fenolik pada tanaman memiliki sejumlah aktivitas biologis yang penting diantaranya sebagai antijamur, antivirus, antibakteri terhadap Salmonella, Clostridium, Bacillus, Chlamydia pneumoniae (penyebab infeksi paru-paru, pneumonia), Vibrio cholerae dan E.coli (Morinaga et al, 2005; Cabrera et al, 2006; Alvesalo et al, 2006; Howell, 2007); antioksidan, mengeluarkan zat kimia sebagai penarik serangga untuk penyerbukan, memberi warna pada tanaman, pergantian warna untuk untuk kamuflase dan pertahanan dari herbivora. Hal ini sesuai dengan penelitian yang dilakukan oleh Dixon and Paiva (1995), diketahui bahwa senyawa fenolik tanaman mengandung antoksidan yang tinggi dan berperan penting untuk melindungi tanaman dari penyakit patogen.

Senyawa fitokimia 3-((3-Acetoxythyl)6-acetoxymethyl-2,4-dimethyl)phenyl)-2- 
methyl-(E)-2-propenyl acetate ini merupakan senyawa baru yang dinamakan dengan "cybrodine" atau biasa disebut dengan cybrodol. dan masuk ke golongan seskuiterpenoid (Ayer and McCaskill, 1981). Adapun rumus molekul cybrodol dapat dilihat pada Gambar 4.

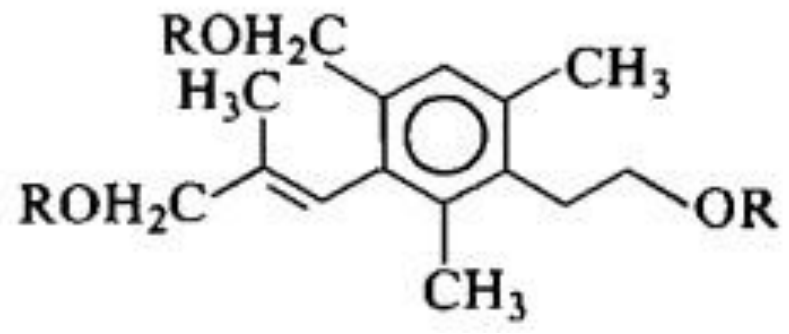

Gambar 4. Struktur cybrodol (Ayer and McCaskill, 1981)

Cybrodol menunjukkan adanya fungsi allyl alkohol (Ayer and McCaskill, 1981). Allyl alkohol (AA) adalah senyawa organik yang umumnya digunakan sebagai bahan mentah pembuatan gliserol, prekursor bahan-bahan senyawa khusus, seperti bahan tahan api, minyak pengering, dan plasticizer (Krahling et al, 2002) dan herbisida (Tomar et al, 2015). Fungsi lain dari allyl alkohol adalah sebagai insektisida, herbisida, fungisida dan antibakteri (ChEBI, 2017).

Seskuiterpen adalah salah satu kelompok terpenoid yang berupa senyawa asiklik dengan banyak kombinasi unik dan terdiri dari 3 unit isoprena (Breitmaier, 2006). Seskuiterpen merupakankomponen minyak atsiri yang berfungsi dalam memberi aroma pada buah dan bunga. Selain itu, seskuiterpen banyak terkandung dalam tanaman obat. Peranan penting seskuiterpen sebagai penolak serangga, insektisida, membantu pertumbuhan (zat pengatur tumbuh), serta anti fungi (Robinson, 1995).

Bahan aktif dari terpenoid terbukti sebagai pestisida alami yang handal (Ansarikimia, 2014). Sedangkan efek farmakologis terpenoid terhadap manusia yaitu mampu menahan pertumbuhan sel

\section{Aknowledgements}

Penulis mengucapkan terima kasih kepada Kementerian Ristekdikti yang telah mendanai penelitian ini melalui Hibah Penelitian Dosen Pemula Tahun 2018. yang berlebih sehingga menghambat pertumbuhan tumor (Robinson, 1995).

Dapat disimpulkan bahwa keempat senyawa fitokimia yang teridentifikasi dari ekstrak metanol jamur Ganoderma lucidum memiliki cincin heterosiklik. Heterosiklik merupakan golongan senyawa yang penting dimana membentuk hampir semua senyawa organik. Senyawa heterosiklik berperan penting sebagai struktur dasar di bidang farmasi (obatobatan), agrokimia dan aktivitas biologis penting lainnya seperti antimikroba, pestisida alami (herbisida, fungisida, dan insektisida), antivirus dan lain-lain (shodhganga.inflibnet.ac.in).

\section{Kesimpulan}

Dari hasil skrining fitokimia terhadap ekstrak metanol jamur Ganoderma lucidum dengan GCMS telah ditemukan senyawa-senyawa baru yaitu thiophene, 2hexyl-; 3-((3-Acetoxythyl)-6acetoxymethyl-2,4-dimethyl)phenyl)-2methyl-(E)-2-propenyl acetate; 2,7Diphenylindole; dan 5-(2-Bromophenyl)7-chloro-2,3-dihydro-1H-1,4benzodiazepin-2-one.

\section{Daftar Pustaka}

Abdel-Fattah, B., Kandeel, M.M., AbdelHakeem, M. \& Fahmy, Z.M. (2006). Synthesis of Certain Fused Thienopyrimidines of Biological 
Interest Journal of the Chinese Chemical Society, 53, 403-412.

Abdelhamid, A.O. (2009). J. Heterocycl Chem, 46, 680-686.

Alvesalo, J., Vuorela, H., Tammela, P., Leinonen, M., Saikku, P. and Vuorela, P. (2006). Inhibitory effect of dietary phenolic compounds on Chlamydia pneumoniae in cell cultures. Biochemical Pharmacology. 71, 735741.

Ansarikimia. (2014). Apa itu Terpen?. https://wawasanilmukimia.wordpress .com/2014/01/15/apa-itu-terpen/ https://wawasanilmukimia.wordpress .com/2014/01/15/apa-itu-terpen/ (diakses pada tanggal 7 September 2018).

Ansary, A.K. \& Omar, H.A. (2001). Synthesis and anti-inflamatory activity of some thieno [2,3d] pyrimidmone derivatives. Bull Faculty Pharm, 39, 17.

Ayer, A.W. \& McCaskill, R.H. (1981). The cybrodins, a new class of sesquiterpenes. Can.J. Chem, 59, 2150

Breitmaier, D. (2006). Sesquiterpenes. Terpenes: Flavor, Fragrances. Pharmaca. Pheromones. Doi:10.1002/9783527609949.ch3. ISBN 9783527609949

Brown, D.J. (1984). Pyrimidines and Their Benzo Derivatives, in Comprehensive Heterocyclic Chemistry (Ed. A. R. Katritzky and C.W. Rees). Volume 3, Oxford: Pergamon Press, 443.

Burnett A.D., Caplen, A.M., Davis, R.H. \& Clader, J. (1994). J. Med. Chem, 37, 1733.

Cabrera, C., Artacho, R. and Gimenez, R. (2006). Beneficial effects of green tea. Journal of the American College of Nutrition. 25, 79-99.

Campos, J., Anon, E. Malo, C.M. \& Rodriguez, M.A. (1999). A versatile synthesis of pyrrolo-, Furo- and Thiono pyridines via photocyclization of 3-amino-2- alkene imines in an acid medium. Tetrahedron, 55, 14079.
Chaman, L. \& Verma, L.R. (2006). Use of certain bio-products for insect-pest control. Indian Journal of Traditional Knowledge, 5(1), 79- 82.

Chaudhary, A., Jha, K.K. \& Kumar, S. (2012). Biological Diversity of Thiophene: Review. Journal of Advanced Scientific Research, 3(3), 03-10.

CheEBI. (2017). CHEBI: 16605 - Allyl Alcohol.

https://www.ebi.ac.uk/chebi/searchId. do?chebiId=CHEBI:16605. (diakses tanggal 7 September 2018).

Cinchana, N.V., Sujan, G.P.S. \& Shruthi, S.D. (2011). In-vitro antioxidant and antibacterial activities of the four synthesized indole derivatives. Research Journal of Pharmaceutical, Biological and Chemical Sciences, 2(2), 353-362.

De-Fatima, A., Modolo, L.V., Conegero, L.S., Pilli, R.A., Ferreira, C.V., Kohn, L.K., de-Carvalho, J.E. (2006). Lactones and their derivatives: biological activities, mechanisms of action potential leads for drug design. Curr. Med. Chem. 13, 3371-3384.

El-Gaby, M.S.A.E.A., Abdel-Hamide S.G, Ghorab, M.M. \& El-Sayed, S.M. (1999). Synthesis and anticancer activity in vitro of some new pyrimidines. Act Pharm, 49, 149158.

Gibson, E.L., Wardel, J., Watts, C.J. (1998). Fruit and Vegetable Consumption, Nutritional Knowledge and Beliefs in Mothers and Children Appetite. 31. 205-228.

Harborne, J.B, (1998). Textbook of Phytochemical Methods: A Guide to Modern Techniques of Plants Analysis $5^{\text {th }}$ Edition, London: Chapman \& Hall Ltd.

Hasler, C.M. and Blumberg, J.B. (1999). Symposium on Phytochemicals: Biochemistry and Physiology. Journal of Nutrition, 129. 756S-757S.

Howell, A.B. (2007). Bioactive compounds in cranberries and their role in prevention of urinary tract 
infections. Molecular Nutrition and Food Research. 51, 732-737.

https://pubchem.ncbi.nlm.nih.gov/compou nd/2-Hexylthiophene (diakses tanggal 7 September 2018).

http://www.chemspider.com/Chemical-

Structure.541189.html (diakses tanggal 7 September 2018).

Illing, I., Safitri, W. \& Erfiana. (2017). Uji Fitokimia Ekstrak Buah Dengen. Jurnal Dinamika, 8(1), 149-158.

Johnson, M., Yamunadevi, M. and Gnaraj, W.E. (2011). Chromatographic fingerprint analysis $\mathrm{f}$ steroids in Aerva lanata L. by HPTLC technique. Asian Pac J of Trop Biomed. 428-433.

Kamra, A. and Bhatt, A.B. (2012). Evaluation of antimicrobial and antioxidant of Ganoderma lucidum extracts against human pathogenic bacteria. Inter J Pharm Sci. 4, 359361.

Kannan, M., Muthusamy, P. and Venkatachalam, U. (2016). Quantification of bioactive components from medicinal herb Ganoderma lucidum using HPTLC and GC-MS techniques. Research Journal of Biotechnology. 11(6): 4957.

Kaushik, J.C., Sanjay A., Tripathi N.N., Arya S. (2002). Antifungal properties of some plant extracts against damping off fungi of forest nurseries. Indian Journal of Forestry, 25, 359361.

Kaushik, N.K., Kaushik, C.H., Verma, A.K. \& Choi, E.H. (2013). Biomedical Importance of Indoles: Review. Molecules, 18, 6620-6662.

Khan, I., Anupama, Singh, B. (2015). 1,4Benzodiazepine: An Overview of Biological Properties. Sci. Revs. Chem. Commun, 5(1), 13-20.

Krahling, L., Krey, J., Jakobson, G., Grolig, J. Miksche, L. (2002). “Allyl Compunds" Ullmann's Encyclopedia of Industrial Chemistry. Weinhem: Wiley-VCH. 7-11.
Kumar, A. \& Singh, C.P. (2013). Synthesis, Characterisation and Biological Activity of Some New Sulpha/Substituted Phenylazo Indoles. International Journal of Science and Research (IJSR), 4(10), 934-938.

Marston, A. (2007). Role of Advances in chromatographic techniques in phytochemistry. Phytochemistry, 68, 2785-2797.

Mathai, K. (2000). Nutrition in the Adult Years. In Krause's Food, Nutrition and Diet Therapy. 10 ${ }^{\text {th }}$ Edition, ed.L.K. Mahan and S. Escott-Stump. 271. 274-275.

Mishra, R. \& Sharma, P.K. (2015). A Review on Synthesis and Medicinal Importance of Thiophene. International Journal of Engineering and Allied Sciences (IJEAS), 1(1), 4659.

Mongevega, A., Aldama, I., Robbani, M.M., \& Fernandez, E. (1980). Heterocycl Chem, 17, 77.

Morinaga, N., Iwamaru, Y., Yahiro, K., Tagashira, M., Moss, J. and Noda, M. (2005). Differential activities of plant polyphenols on the binding and internalization of cholera toxin in vero cells. Journal of Biological Chemistry. 280, 23303-23309.

Nasr, M.N. \& Gineinah, M.M. (2002). Pyrido[2,3- $d$ ]pyrimidines and pyrimido[5', $\quad$ 4':5,6]-pyrido[2,3$d$ pyrimidines as new antiviral agents: Synthesis and biological activity. Arch Pharm, 335, 289-295.

Orole, O.O. (2016). GC-MS Evaluation, Phytochemical and Antinutritional Screening of Ganoderma lucidum. Journal of Advances in Biology \& Biotechnology, 5(4): 1-10.

Petrie, C.R., Cottam, H.B, Mekerman, P.A., Robins, R.K. \& Revankar, G.R. (1985). Synthesis and biological activity of 6-azacadeguonomycin and certain 2,4,6-trisubstitutedpyrazolo[3,4- $d]$-pyrimidine 
ribonucleosides. J. Med. Chem, 28, 1010-1016.

Pi, C., Quan, Z., Yun-Bao, M., Zhi-Yong, J., Xue-Mei, Z., Feng-Xue, Z. and JiJun, C. (2008). Synthesis and in vitro anti-hepatities B virus activities of 4aryl-6-chloroquinolin-2-one and 5aryl-7-chloro-1,4-benzodiazepine derivatives. Bioorg. Med. Chem. Lett. 18, 3787-89.

Patterson, R. (2016). Ganoderma - A therapeutic fungal biofactory. Phytochemistry, 67: 1985-2001.

Shimkin, A.A., Mailian, A.K., Shirinian, V.Z. \& Krayushkin, M.M. (2007).

Synthesis of $1 \mathrm{H}-$ and $3 \mathrm{H}-$ [1]Benzothieno[3,2- $b$ ]pyrroles. Synthesis, 17, 2706-2710.

shodhganga.inflibnet.ac.in/bitstream/1060 3/8729/7/07_chapter\%201.pdf.

Chapter-1. An overview of heterocyclic compounds and their biological significance (diakses tanggal 20 September 2018)

Sommen, G., Comel, A. \& Kirsch, G. (2003). Preparation of thieno[2,3b]pyrroles starting from ketene-N,Sacetals, Tetrahedron, 59, 1557-1564.

Soria, C.C., Chang, Y. \& Weiss, D.S. (2006). Mechanism of action of benzodiazepines on $\mathrm{GABA}_{\mathrm{A}}$ receptors. British J. Pharmacol, 148(7), 984-990.

Raju, G.N., Sai, K.B., Meghana, M.S., Chandana, K., Suresh, P.V. \& Nadendla, R.R. (2015). Synthesis, Characterization and Biological Activity of Indole-2-carboxylic acide derivatives. International Journal of Pharmaceutical Chemistry, 5, 202206.

Randjelovic, P., Veljkovic, S., Stojilkovic, N., Sokolovic, D., Ilic, I., Lacetic, D., Randjelovic, D. (2015). The Beneficial Biological Properties of Salicyclic Acid. Acta Facultatis Medicae Naissensis, 32(4), 259-265.

Roth, B. \& Cheng, C. (1982). In Progress in Medicinal Chemistry (Eds. G.B.
Ellis and G.E. West). Vol 19, new York: Elsevier Biomedical Press, 267. Robinson, T. (1995). Kandungan Organik Tumbuhan Tinggi. Bandung: ITB.

Thompson, D., Mitchell, S., Clarke, K., Sarden, K. \& Aiken, K.S. (2012). 2Bromophenyl Salicylate. Molbanky.

Tomar, S.R., Golla, U \& Bandi, G. (2015). Molecular Cytotoxicity Mechanisms of Allyl Alcohol (Acrolein) in Budding Yeast. Chemical Research in Toxicology. 28(6), 1246-1264.

Umirna (2016). Analisis Kandungan Senyawa Metabolit Sekunder Dari Kulit Buah Kecombrang (Etlingera elatior) Dengan Metode Spektrofotometer UV-Vis. Skripsi. Sulawesi Selatan: Program Studi Kimia Fakultas Sains Universitas Cokroaminoto Palopo. 